Revista da Universidade Estadual de Alagoas/UNEAL

e-ISSN 2318-454X, Ano 12, Vol. 12 (4), outubro/dezembro (2020)

\title{
Hygienic-sanitary conditions of food sold in the public market and open market in the municipality of Arapiraca-AL
}

\section{Condições higiênico-sanitárias dos alimentos comercializados no mercado público e feira livre do município de Arapiraca-AL}

Lucineide Santos da Silva ${ }^{(1)}$; Claudimary Bispo dos $\operatorname{Santos}^{(2)}$

${ }^{(1)}$ Graduanda em Ciências Biológicas; Universidade Estadual de Alagoas - UNEAL; Arapiraca,Alagoas; lucineideigor0@ gmail.com; ${ }^{(2)}$ Professora Assistente; Universidade

Estadual de Alagoas - UNEAL; claudimarybs@ hotmail.com

E-mail do autor correspondente: lucineideigor0@gmail.com

Recebido em outubro e aceito em dezembro 2020.

Resumo - As feiras e mercados públicos oferecem diversos produtos e serviços em um único local, revelam hábitos e manifestações culturais, sendo de grande importância sócioeconômico-cultural para o município. Porém, os alimentos muitas vezes são comercializados em condições que propiciam a contaminação por microrganismos quando não são adotadas práticas adequadas de manipulação e exposição. Sendo assim, o objetivo deste estudo foi avaliar as condições higiênico-sanitárias dos alimentos perecíveis comercializados na feira livre e no mercado público do município de Arapiraca-AL. Foram realizadas duas visitas semanais em dezembro/2018, uma visita no Mercado Público, e a outra na feira livre, que ocorre no dia de segunda-feira, localizada nas ruas próximas ao Mercado Público. Os alimentos avaliados foram frutas e hortaliças, carnes e pescados, através de um roteiro de inspeção (check-list) baseado na Resolução da Diretoria Colegiada - RDC nº 216/2004 da Agência Nacional de Vigilância Sanitária - ANVISA, cujos itens selecionados foram condições de comercialização, condições de armazenamento, condições de higiene dos manipuladores e das instalações. Na maioria dos aspectos avaliados, principalmente na feira livre, os resultados foram insatisfatórios, devido ao não cumprimento das normas vigentes. Conclui-se que a feira livre não possui estrutura mínima para que possam ser aplicadas as normas higiênico-sanitárias na venda de carnes e pescados e o mercado público apesar de ter uma melhor infraestrutura, os feirantes desrespeitam essas normas.

Palavras-chave: Comercialização; Feirantes; Roteiro de inspeção.

Abstract - Public fairs and markets offer several products and services in a single location, reveal habits and cultural manifestations, being of great socio-economic-cultural importance for the municipality. However, food is often marketed under conditions that provide 
contamination by microorganisms when adequate handling and exposure practices are not adopted. Therefore, the objective of this study was to evaluate the hygienic-sanitary conditions of perishable foods sold in the open market and in the public market in the city of ArapiracaAL. Two weekly visits were made in December/2018, one in the Public Market, and the other in the open market, which takes place on Monday, located in the streets near the Public Market. The evaluated foods were fruits and vegetables, meat and fish, through an inspection script (check-list) based on the Resolution of the Collegiate Board - RDC n ${ }^{\circ}$ 216/2004 of the National Health Surveillance Agency - ANVISA, whose selected items were conditions of commercialization, storage conditions, hygiene conditions of the handlers and installations. In most of the aspects evaluated, mainly in the open market, the results were unsatisfactory, due to the non-compliance with the current rules. It is concluded that the free market has no minimum structure so that the hygienic-sanitary standards can be applied in the sale of meat and fish and the public market despite having a better infrastructure, the market vendors disregard these standards.

Keywords: Commercialization; Fairkeepers; Inspection roadmap.

\section{Introdução}

A feira livre é um dos locais mais tradicionais em que se comercializam alimentos a varejo, sendo frequentada, em sua maior parte, por parcela da população que já possui o hábito de ir à feira (GOMES et al., 2012). Além disso, as feiras e mercados públicos podem ser considerados patrimônio culturais de uma cidade, pois oferecem diversos produtos e serviços em um único local, revelam hábitos e manifestações culturais, sendo de grande importância sócio-econômico-cultural para o município (OLIVEIRA et al., 2008).

Segundo Santos et al. (2013), os consumidores têm preferência na aquisição de alimentos vendidos em feiras livres, por considerarem estes alimentos frescos e de qualidade superior. Porém, estes produtos muitas vezes são comercializados em condições que propiciam a contaminação por microrganismos quando não são adotadas práticas adequadas de manipulação e exposição dos alimentos para a venda (SANTOS et al., 2013).

A carne é um meio de cultura ideal para o desenvolvimento dos microrganismos e é ainda mais propícia a contaminação quando as condições higiênico-sanitárias do ambiente e do manipulador são inadequadas, assim como temperatura de armazenagem, a higiene e conservação dos utensílios e equipamentos (COUTINHO et al, 2007).

$\mathrm{O}$ pescado representa um dos alimentos de maior perecibilidade estando sujeito à contaminação pelos mais variados microrganismos, adquiridos já no ambiente aquático, portanto necessita-se de bastante atenção, desde a sua captura, transporte até na conservação pelo frio (CONSTANTINIDO, 1994). A forma de acondicionamento de tais produtos alimentícios em mercados encontra-se na maioria das vezes de maneira indevida, sendo 


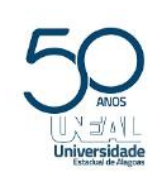

Revista Ambientale

Revista da Universidade Estadual de Alagoas/UNEAL

e-ISSN 2318-454X, Ano 12, Vol. 12 (4), outubro/dezembro (2020)

comercializados sem qualquer tipo de refrigeração, em isopores sem a presença de gelo, ou sobre bancadas à temperatura ambiente.

A temperatura é um dos fatores mais relevantes na questão da conservação dos alimentos, uma vez que o crescimento microbiológico acontece no intervalo $-8^{\circ} \mathrm{C} \mathrm{e} 90^{\circ} \mathrm{C}$, sendo a temperatura ambiente considerada ideal para o desenvolvimento de microrganismos patógenos (OLIVEIRA, 2013).

Os produtos como frutas e hortaliças são alimentos bastante comercializados em feiras livres e mercado público requerendo alguns cuidados especiais para sua comercialização. Observa-se que esses produtos são comercializados em bancadas de madeira ou expostos em lonas sobre o chão, gerando risco de contaminação e condições inadequadas para consumo (FARIAS et al., 2010).

Nos últimos anos, diversos estudos vêm mostrando os problemas observados em feiras livres, cujas dificuldades ou deficiências estão relacionadas às más condições higiênicosanitárias das bancas, dos produtores/manipuladores e dos produtos comercializados (higienização incorreta). Tais condições fazem com que as feiras sejam consideradas locais com características específicas, que podem favorecer o crescimento e proliferação de microrganismos (XAVIER et al, 2009).

Nota-se que o aparecimento de doenças transmitidas por alimento (DTA) tem aumentado em todo o mundo em decorrência da maior urbanização da sociedade que acarreta transporte de longas distâncias, globalização do comércio de alimentos, mudanças nos hábitos alimentares e nas práticas agropecuárias, além dos fatores relacionados com as inadequações dos alimentos perecíveis comercializados nas feiras (OLIVEIRA, 2010).

No Nordeste é bastante comum que as cidades tenham mercado público, onde geralmente as feiras acontecem em dias definidos durante a semana, havendo dois espaços organizados para as pessoas comercializarem, um localizado dentro do prédio público e outro ao ar livre no entorno do mesmo. Neste sentido, são frequentados tanto pela população local, como por pessoas de diversas cidades vizinhas (SILVA et al., 2009).

A feira livre, na cidade de Arapiraca, foi a propulsora para sua expansão e contribuiu para o desenvolvimento local, quando esse município, ainda era um povoado. A feira era considerada a maior manifestação cultural da região do Agreste e uma das principais influenciadoras do processo de sua emancipação. Porém, com o passar dos anos a cidade cresceu e essa feira que tinha tomando uma proporção enorme, passou a gerar problemas urbanos. Assim, foi transferida para junto do mercado público, diminuindo de tamanho e continua funcionando às segundas-feiras, sendo ainda parte importante da vida de Arapiraca. Atualmente, existem feiras livres espalhadas por vários bairros, em diferentes dias da semana (ARAPIRACA, 2017).

Neste contexto, as feiras são consideradas como um local propício para a disseminação de DTA, através da intensa circulação de produtos e pessoas no mesmo ambiente aliados as condições indesejáveis de higiene e sanidade, tornando-se de grande importância o conhecimento das condições de comercialização e manipulação de seus produtos. Portanto, este 


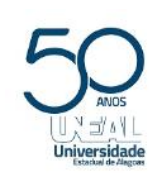

Revista Ambientale

Revista da Universidade Estadual de Alagoas/UNEAL

e-ISSN 2318-454X, Ano 12, Vol. 12 (4), outubro/dezembro (2020)

estudo teve como objetivo avaliar as condições higiênico-sanitárias dos alimentos perecíveis comercializados na feira livre e no mercado público do município de Arapiraca-AL.

\section{Procedimento metodológico}

Esta é uma pesquisa quanti-qualitativa, descritiva e de delineamento transversal que foi realizada no mercado municipal e em uma feira-livre da cidade de Arapiraca, Estado de Alagoas, durante o mês de dezembro de 2018. O município pertence à Mesorregião do Agreste Alagoano, localiza-se a oeste da capital do estado, distando desta cerca de $130 \mathrm{Km}$. Sua população foi estimada para 2019 em 231.747 habitantes (IBGE, 2019), sendo assim, o segundo mais populoso do estado e o primeiro de sua microrregião. Apresenta 19.1\% de domicílios com esgotamento sanitário adequado, $74.4 \%$ de domicílios urbanos em vias públicas com arborização e $12.2 \%$ de domicílios urbanos em vias públicas com urbanização adequada (presença de bueiro, calçada, pavimentação e meio-fio) (IBGE, 2019).

Para a coleta dos dados foram realizadas duas visitas semanais, uma visita no Mercado Público, e a outra na maior feira livre da cidade, que ocorre no dia de segunda-feira, localizada nas ruas próximas ao Mercado Público. Foi utilizado um roteiro de inspeção (check-list) baseado na Resolução da Diretoria Colegiada - RDC nº 216/2004 da Agência Nacional de Vigilância Sanitária - ANVISA, normas estabelecidas para a comercialização dos alimentos (BRASIL, 2004). Os itens selecionados foram apenas aqueles que pudessem ser aplicados para averiguação das condições de comercialização, condições de armazenamento, condições de higiene dos manipuladores e das instalações.

Os alimentos avaliados foram frutas e hortaliças, carnes e pescados. Em relação aos itens avaliados, destaca-se: 1. Higiene pessoal dos feirantes - uso de jaleco ou uniforme sobre a roupa; cuidados com o cabelo, unhas e uso de adornos; 2 . Limpeza da área externa e interna do local; 3. Limpeza dos equipamentos e utensílios; 4. Origem da água utilizada e destino das águas utilizadas; 5. Os alimentos perecíveis são expostos e/ou armazenados de que forma; armazenados em caixas no chão?; 6. Presença de lixo e de entulho; 7. Presença de animais; 8. Tipos de bancas - estrutura (armações); 9. Instalações sanitárias - banheiros públicos? 10. Existência de lixeira individual na banca - qual o local de deposição dos resíduos (lixo) produzidos?; 11. Controle integrado de vetores e pragas urbanas.

Os check-list foram aplicados no período matutino e as opções de respostas foram: "Conforme" (C) - quando a banca atendeu ao item observado e "Não Conforme" (NC) - quando o mesmo apresentou Não-conformidade.

\section{Resultados e discussão}

\section{Frutas e hortaliças}




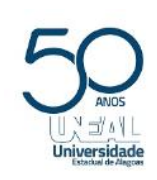

Revista Ambientale

Revista da Universidade Estadual de Alagoas/UNEAL

e-ISSN 2318-454X, Ano 12, Vol. 12 (4), outubro/dezembro (2020)

Figura 1. Hortaliças expostas nas bancas das feiras;
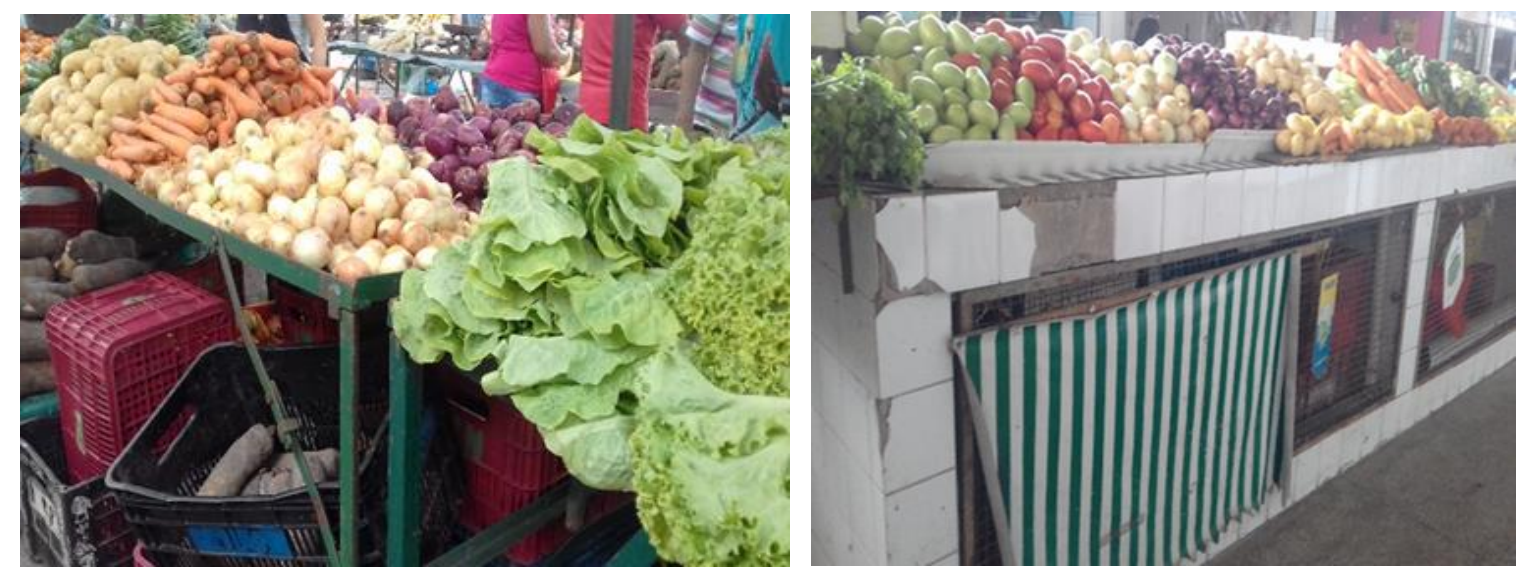

No mercado público existem 15 boxes que comercializam frutas e hortaliças e na feira livre 10 bancas. $\mathrm{Na}$ análise dos quesitos que compõe a higiene pessoal dos manipuladores (feirantes), observou-se que não utilizavam uniforme adequado e completo, sem uso de jaleco, luvas e toucas, apenas usavam aventais com bolsos para facilitar a manipulação de dinheiro durante as vendas dos produtos. A maioria não prendia os cabelos devidamente e nem possuíam unhas curtas e limpas, além disso, foi visto que alguns usavam adornos pessoais. Supondo-se que os feirantes tenham desconhecimento e/ou desrespeito as boas práticas de manipulação, conforme figura 1.

Resultados semelhantes foram obtidos na pesquisa de Silva \& Menelau (2015) realizada em diferentes mercados públicos e feiras-livres de Recife, onde os autores observaram que os manipuladores dos alimentos desconheciam e/ou desrespeitavam as boas práticas de manipulação. Segundo os pesquisadores, os vendedores mantinham o contato com dinheiro ao mesmo tempo em que manipulavam os alimentos, não utilizavam uniforme adequado, além de tossir e espirrar próximo as hortifrútis, tudo isso pode ocasionar a contaminação dos vegetais ali comercializados.

No que diz respeito às instalações, no mercado público as bancadas dos boxes possuem revestimento de cerâmica, porém, em alguns locais encontram-se quebradas e com rachaduras. Quanto à feira livre as bancas são de zinco com proteção de lonas na sua cobertura, as bancas já estavam com ferrugem em toda a sua estrutura.

Foi identificada a ausência de locais adequados para a estocagem de lixo, o que acaba acarretando na presença de resíduos - restos de hortaliças e sacolas plásticas espalhadas pelo chão, nas imediações dos pontos de vendas das bancas, na feira livre. No mercado público, os lixeiros são colocados no hall central, ou seja, não possui lixeiro individualizado, dificultando a estocagem para posterior destino final dos resíduos. Entretanto, no momento da realização do check-list não foi constatado resíduos nesses boxes. Foi percebido também que a limpeza das áreas internas e externas de comercialização de frutas e hortaliças é feita pelos funcionários da 


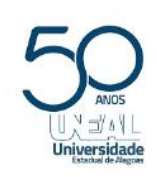

Revista Ambientale

Revista da Universidade Estadual de Alagoas/UNEAL

e-ISSN 2318-454X, Ano 12, Vol. 12 (4), outubro/dezembro (2020)

limpeza pública, enquanto, os feirantes são responsáveis pela limpeza dos seus equipamentos e utensílios.

As frutas e hortaliças, além de serem comercializadas nos boxes do mercado também são expostas e armazenadas para a venda em sacos de nylon, caixas agrícolas de plástico sobre pallets de madeira, na área externa do mercado (Figura 3). Na feira livre, essas caixas são colocadas diretamente no chão; e as bananas são colocadas sobre folhas da bananeira no chão (Figura 4). Foram verificados resíduos de frutas, água suja e sacolas plásticas no local de armazenamento e com muitas sujidades por toda a área externa do mercado e da feira livre.

Figura 3 e 4 - Condições de armazenamento de frutas e hortaliças no mercado público e hortaliças na feira livre.
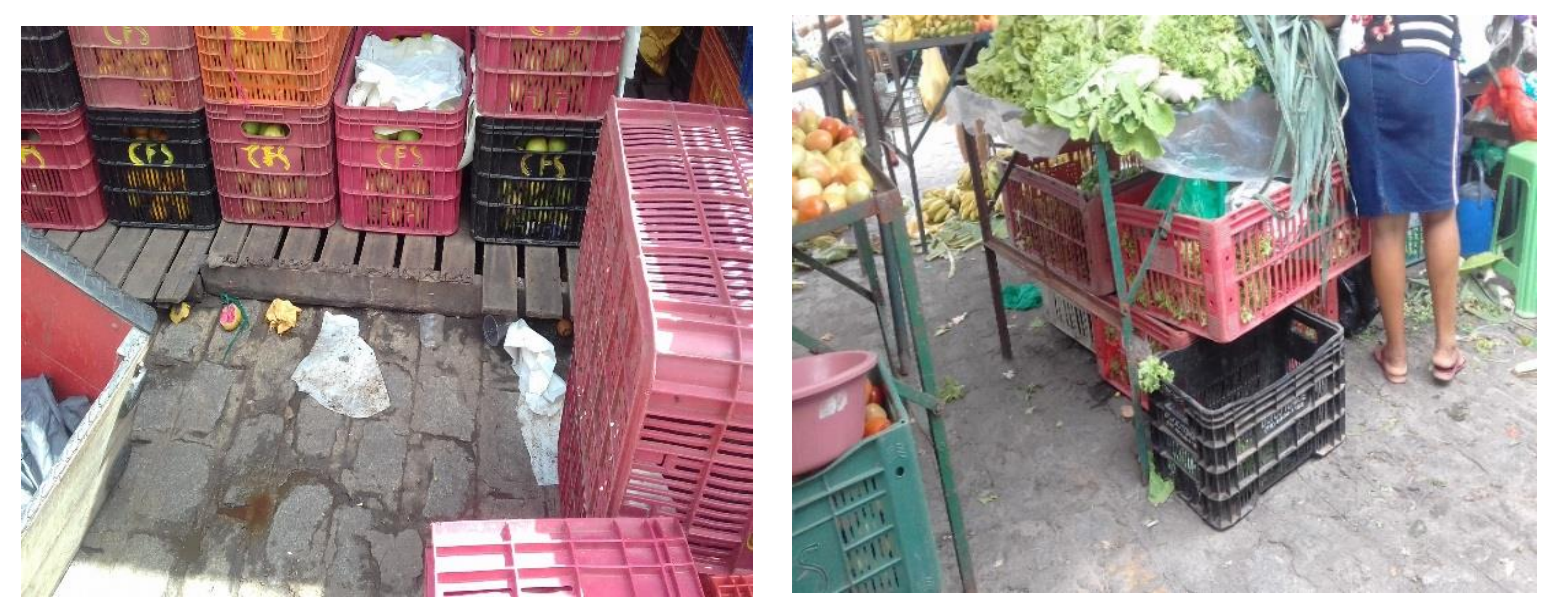

No geral, através dos itens observados, pôde-se perceber que a comercialização de frutas e hortaliças não está em conformidade com as normas relativas às condições higiênicosanitárias. Sendo assim, esses fatores observados podem oferecer risco de contaminação aos alimentos ali vendidos e, consequentemente, pôr em perigo a saúde dos consumidores.

Sousa (2017) ao analisar as condições higiênico-sanitárias das frutas e hortaliças comercializadas no mercado público e em uma feira-livre da cidade de Capanema, no estado do Pará, constatou que na maioria dos casos os alimentos não são armazenados de forma segura, não estando protegidos contra insetos, poeira e outros fatores que podem pôr em risco a qualidade dos mesmos. Além disso, as frutas e hortaliças são armazenadas em bancadas de madeira, que na maioria das vezes encontram-se sujas e úmidas, podendo contaminá-las.

\section{Carnes e pescados}

No mercado público existem 79 boxes de carnes e 18 boxes de pescados, já na feira livre há 30 bancas de carnes e 25 de pescados. Ao ser observada a higiene dos manipuladores (feirantes) foi constatado que eles não têm o hábito do uso de jalecos e poucos usavam aventais. 


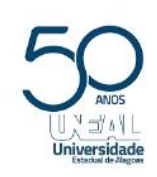

Revista Ambientale

Revista da Universidade Estadual de Alagoas/UNEAL

e-ISSN 2318-454X, Ano 12, Vol. 12 (4), outubro/dezembro (2020)

Também não usavam luvas e toucas, apenas luvas anticorte em algumas bancas e boxes. Porém, foi comum vê-los com adornos, relógios, braceletes e unhas com esmalte.

Estudos de Cavalcanti et al. (2014) e Carneiro (2018) também verificaram que a maioria dos feirantes não faziam uso de toucas e aventais. Sousa et al. (2012) ressaltam a importância do uso destas vestimentas para evitar o contágio indireto de doenças alimentares.

No Brasil um dos maiores problemas no controle higiênico-sanitário dos produtos cárneos negociados em feiras livres, é a resistência por parte dos comerciantes em se adaptar as práticas higiênicas, já que, os hábitos de higiene pessoal, são passados de pai pra filho por gerações. Sendo assim, esses hábitos não são facilmente mudados apenas com imposição de normas, oferta de cursos ou fiscalização (SILVA, 2015).

No quesito estrutura das bancas e dos boxes pôde-se perceber que as bancas utilizadas para comercialização de carnes e pescados na feira livre são de zinco com proteção de lonas na sua cobertura, no mesmo padrão das frutas e hortaliças, possuindo ferrugem em todas as suas extremidades (figura 5).

No mercado público foi visto que a bancada dos boxes de carnes e pescados é de mármore, com estrutura de cimento e tijolos. No entanto, o estado de conservação dos boxes não estava bom, pois, foi visto rachaduras, desgastes no revestimento e acúmulo de sujeira nas frechas das rachaduras, podendo ocasionar contaminações aos alimentos (figura 6). Ao comparar as condições estruturais entre os dois ambientes, no mercado público apesar dos boxes apresentarem problemas, as bancas nas feiras livres possuíam uma maior precariedade em suas instalações.

Figura 5 - Bancas da feira livre com ferrugem.
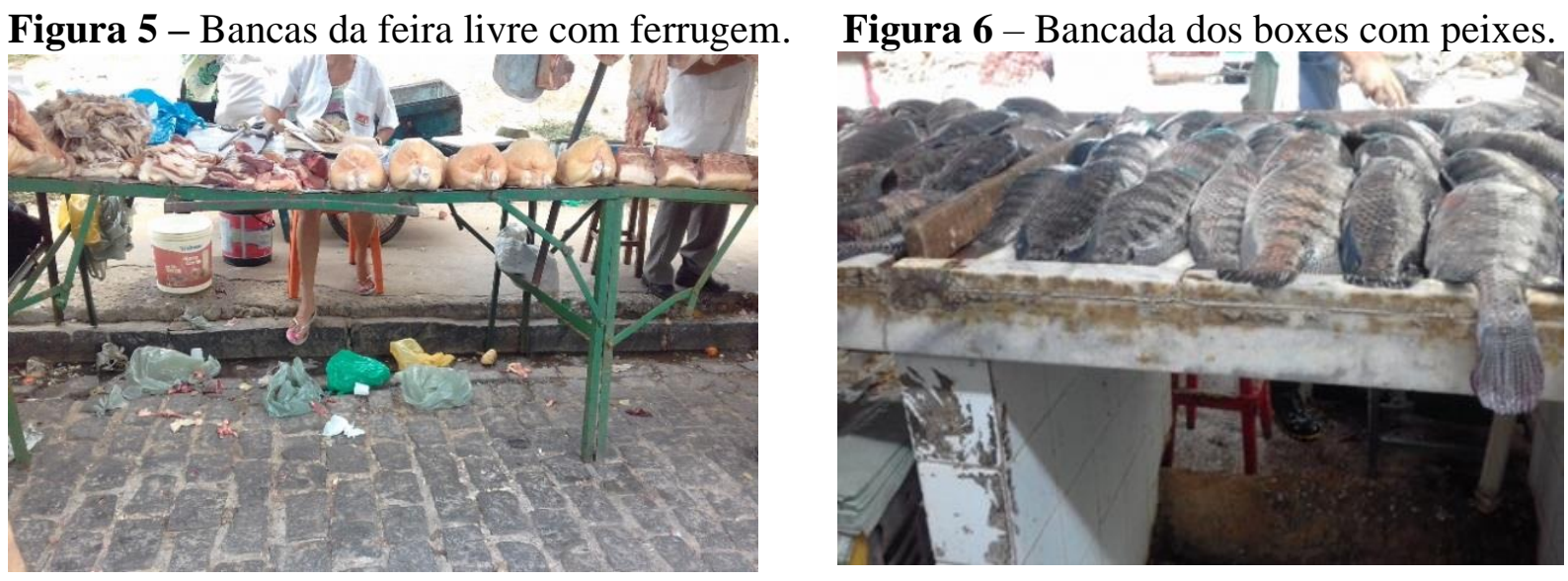

Fonte: Autoria própria

Em relação ao armazenamento, as carnes e pescados ficavam expostos a diversos contaminantes, mantidos em temperatura ambiente durante todo período de comercialização, situação verificada nos dois ambientes (figura 7). Na bancada dos boxes, as aves abatidas estavam em bandejas de alumínio desgastadas (figura 8), ou envolvidas em saco plástico sobre as bancas enferrujadas na feira (figura 5). Os peixes expostos diretamente nas bancadas dos 


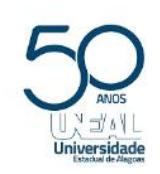

Revista Ambientale

Revista da Universidade Estadual de Alagoas/UNEAL

e-ISSN 2318-454X, Ano 12, Vol. 12 (4), outubro/dezembro (2020)

boxes e nas bancas da feira e as carnes vermelhas penduradas em ganchos, os quais se encontravam em bom estado de conservação, já as vísceras expostas diretamente nas bancas ou em cima de plásticos, papelões e panos.

Figura 7- Carnes expostas à temperatura ambiente. Figura 8 - Aves abatidas expostas.
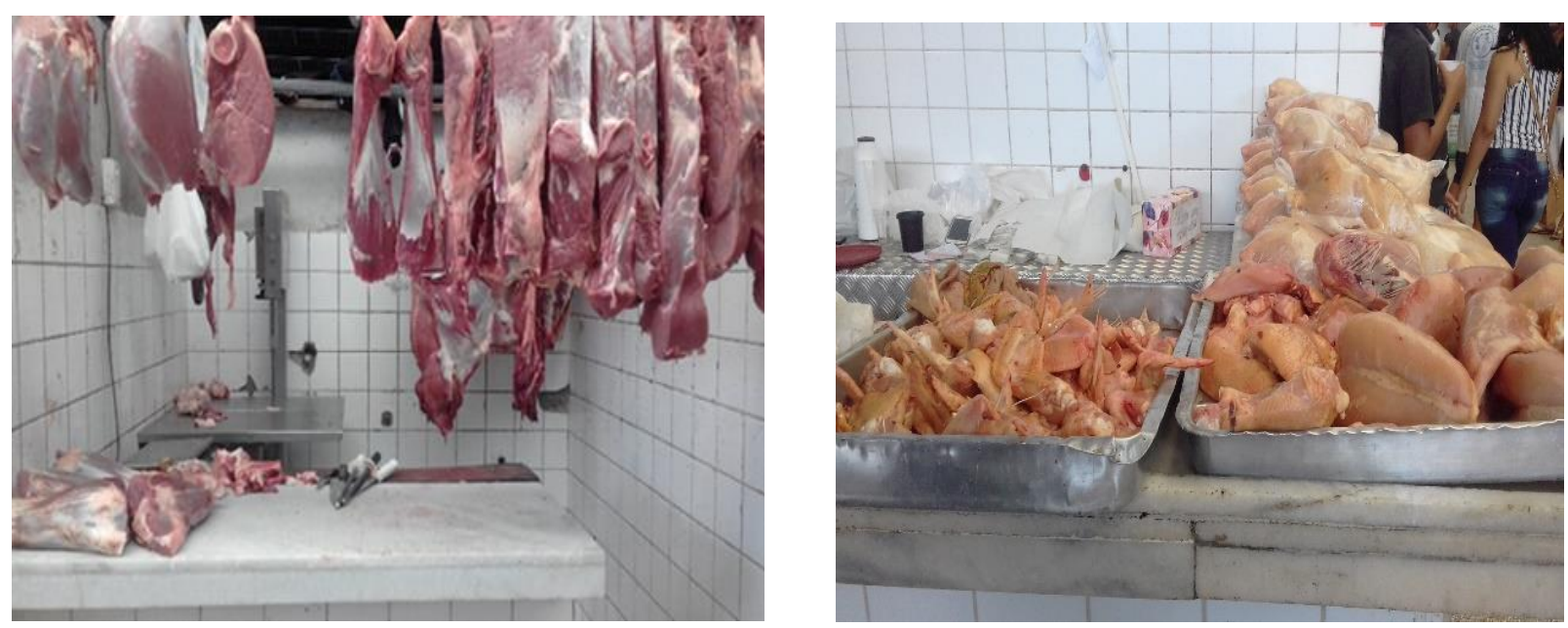

Silva (2015) verificou nas feiras livres de Jiquiriçá-Ba, que as carnes eram comercializadas em temperatura ambiente durante todo período de comercialização, o que favorece a proliferação microbiana, principalmente por estar entre $5-60^{\circ} \mathrm{C}$, zona de perigo quanto ao crescimento de patógenos (BRASIL, 2004). Outro resultado semelhante foi observado por Ferreira et al. (2010), em feiras livres de municípios da Zona da Mata na região Norte do estado de Pernambuco, onde as carnes eram comercializadas nas mesmas condições. Isso reforça que esse método ainda vem sendo adotado e permitido em várias cidades do Brasil, onde ocorre a venda indiscriminada de carne, em temperatura ambiente.

De acordo com o Decreto-Lei n. 207 (BRASIL, 2004), as carnes e seus derivados devem estar protegidos da ação clima, poeiras ou até mesmo do contato das pessoas. Sem contar que durante a distribuição ou comercialização, as carnes devem ser conservadas às temperaturas adequadas, como: refrigerada (entre $-2^{\circ} \mathrm{C} \mathrm{e} 7^{\circ} \mathrm{C}$ ), congelada (temperatura inferior a $-12^{\circ} \mathrm{C}$, com tolerância máxima de $3^{\circ} \mathrm{C}$ ) ou ultracongelada (inferior a $-18^{\circ} \mathrm{C}$ ).

A não utilização de gelo na conservação de pescado foi verificado no presente trabalho e em outros (BARBOSA et al.,2016; FARIAS, 2006; SILVA-JÚNIOR, 2008; SILVAJÚNIOR, 2013; MEDEIROS-JÚNIOR, 2015), demonstrando que essa norma vem sendo desrespeitada há muito tempo. Silva-Júnior et al. (2013) destacaram que a relação tempotemperatura contribui diretamente para o desenvolvimento de microrganismos, ocasionando grande impacto na qualidade de alimentos caso seja mantido de maneira incorreta. 


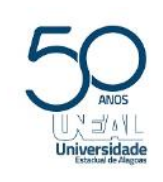

Revista Ambientale

Revista da Universidade Estadual de Alagoas/UNEAL

e-ISSN 2318-454X, Ano 12, Vol. 12 (4), outubro/dezembro (2020)

Quanto ao quesito higiene dos utensílios utilizados para manipulação de carne e pescados, como: facas, arco de serra, amolador chaira, serra fita para ossos, bandejas e descamador de peixes, na sua maioria não estavam em conformidade com as normas da ANVISA (RDC n ${ }^{\circ}$ 216/2004). Foi observado o uso de faca peixeira enferrujada (figura 8), poucos feirantes usavam utensílios cortantes adequados (figura 9), no geral, estavam em mal estado de conservação.

O uso de tabuas de madeira para cortes de carne e pescados desgastadas e com frechas sendo propícias para acúmulo de resíduos (figura 8). Foi verificada também a presença de bandejas de alumínio e de plástico desgastadas e sem higiene. Assim, no geral, foi notória a falta de higiene nos dois ambientes, mercado público e feira livre.

Sousa et al. (2012), observaram em sua pesquisa que a maioria dos utensílios e equipamentos como facas, serras e balanças estava desgastada e sem higiene adequada. Além disso, as carnes quando não estavam expostas penduradas em ganchos, se apresentavam em superfícies de madeira e alvenaria danificada.

Figura 8 - Utensílios inadequados.

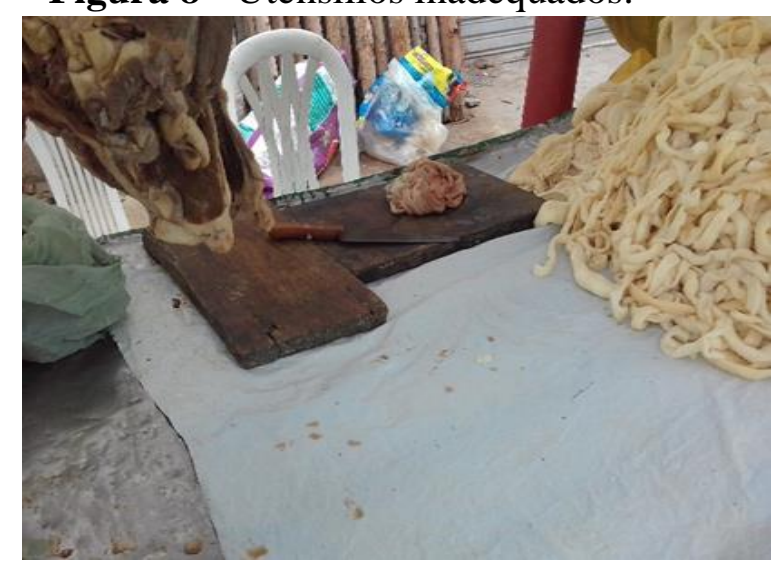

Figura 9 - Utensílios adequados

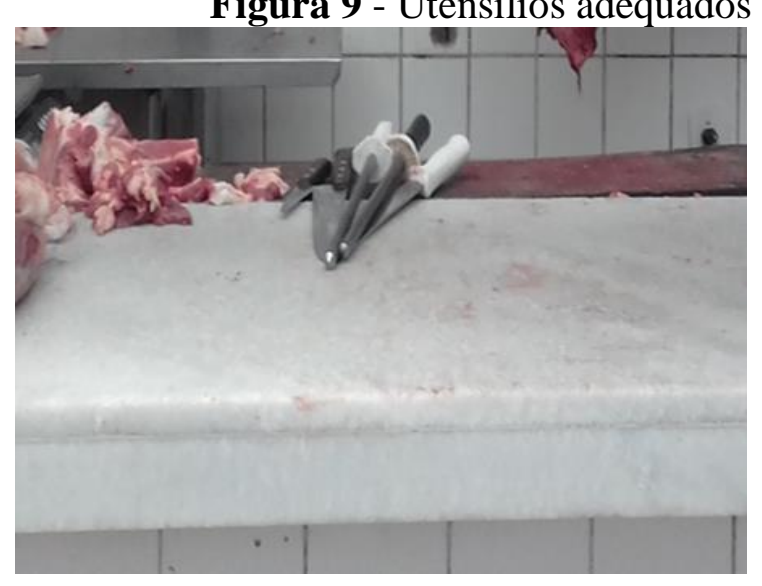

Fonte: Autoria própria

Em relação à água utilizada pelos manipuladores, foi visto que é de origem de um poço específico do mercado público e do sistema de abastecimento de água do município. No mercado público e principalmente na feira livre, por ocorrer a falta de água corrente nos locais de venda dos alimentos, os comerciantes armazenam água em bacias ou baldes (figura 10); e a mesma água utilizada para lavar os alimentos era também utilizada para lavagem das mãos. Quanto ao destino das águas utilizadas no mercado público, existe o esgotamento sanitário, enquanto na feira livre são liberadas em via pública. 
Figura 10 - Armazenamento de água em feira livre

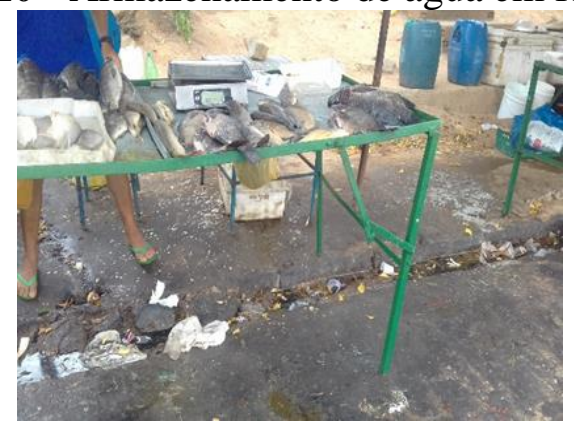

Fonte: Autoria própria

Comumente, os locais de venda em feiras livres carecem de infraestrutura adequada, muitas delas não possuem acesso à água potável e sanitários para os frequentadores, como foi constatado no presente estudo, podendo aumentar a proliferação de agentes causadores de doenças. Carneiro (2018) e Sousa et al. (2012) relataram a mesma problemática na feira de carnes, revelando as condições precárias das instalações destinadas a comercialização de produtos de origem animal e a dificuldade de higienização das mesmas.

A limpeza das áreas externas (feira livre) e internas (mercado público) referentes a comercialização de carnes e pescados é realizada pelos funcionários da secretaria de limpeza da prefeitura, assim como foi visto na feira das frutas e hortaliças. Na feira livre foi comum ver a presença de acúmulo de lixo e diversificação de produtos cárneos nas bancas (figura 11). No mercado público, alguns boxes possuem lixeiros, cuja limpeza, inclusive dos utensílios, é feita por cada feirante responsável pelo seu boxe. Porém, a falta de limpeza foi vista com frequência, havia resíduos de ossos, escamas de peixes, restos de vísceras, etc (figura 12).

Nos estudos de Carneiro (2018) e Cavalcanti et al. (2014) foi observado que a maioria das bancas apresentavam alimentos separados por categoria, fato esse importante pois permite minimizar o risco de eventuais contaminações cruzadas de produtos, ou seja, o agrupamento por categoria possibilita maior eficiência e controle das doenças transmitidas por alimento.

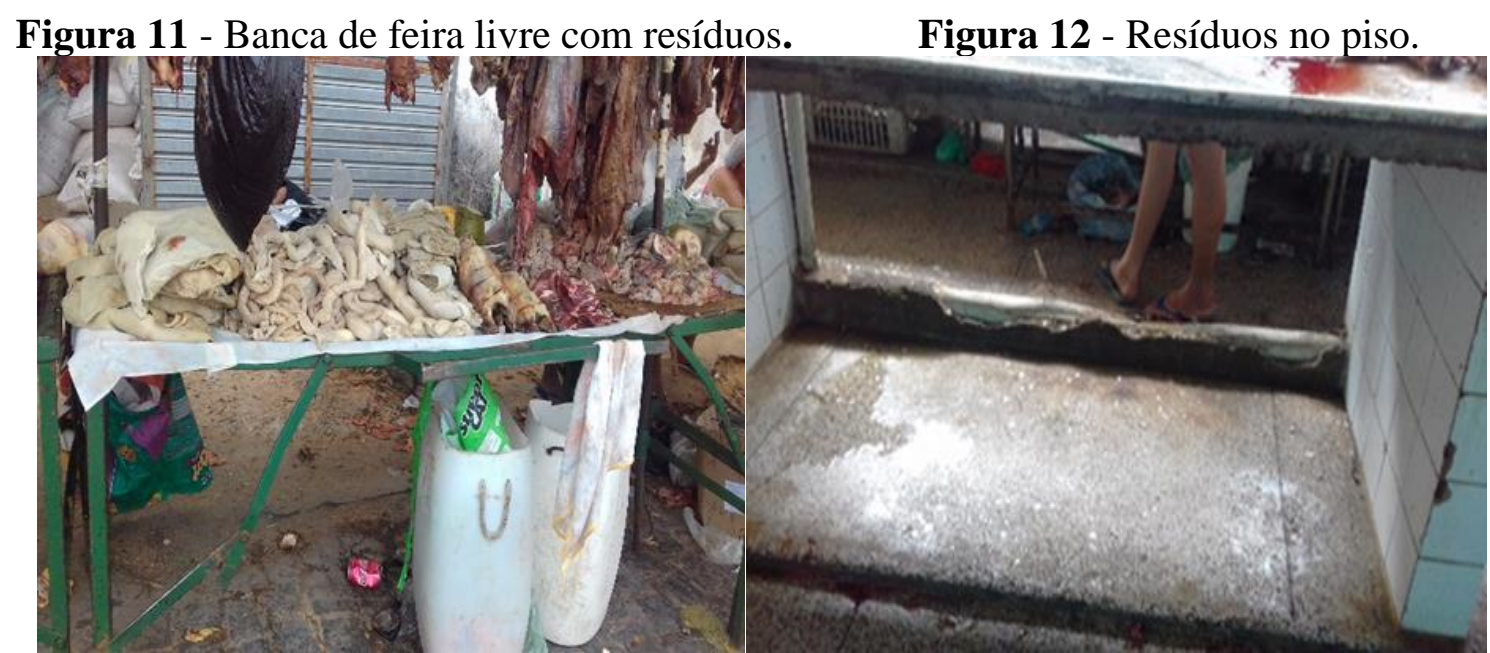

Os resíduos sólidos (lixo) da feira livre e do mercado público são depositados em dois containers abertos que estão localizados na área externa do mercado em via pública, para 


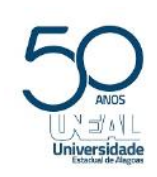

Revista Ambientale

Revista da Universidade Estadual de Alagoas/UNEAL

e-ISSN 2318-454X, Ano 12, Vol. 12 (4), outubro/dezembro (2020)

posteriormente ser levado para a Central de Tratamento de Resíduos - CTR (figura 13). Segundo a RDC no 216/2004 os resíduos devem ser frequentemente coletados e estocados em local fechado e isolado da área de armazenamento dos alimentos, para que sejam evitados focos de contaminação e atração de vetores e pragas urbanas.

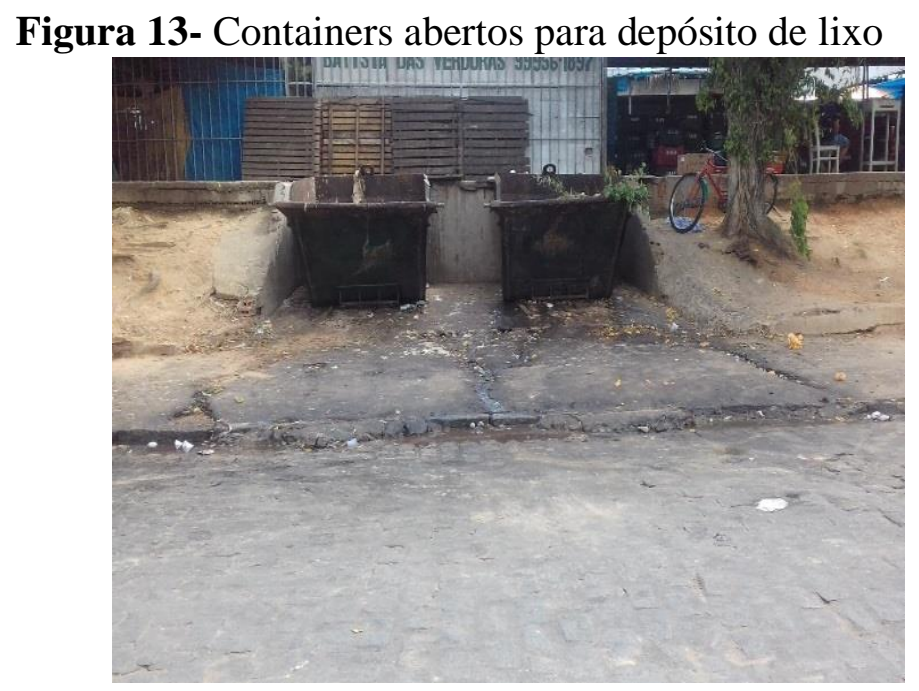

Fonte: Autoria própria

No mercado público, apesar da entrada de cães e gatos não ser permitido, não é possível evitar à aproximação deles. Na feira livre, principalmente, não é possível evitar que esses animais circulem. Dessa forma, comumente, foi visto a presença de animais ao redor do mercado público e circulando na feira livre.

Ainda em relação a presença de animais errantes, como cães e gatos, no estudo de Carneiro (2018) também foi constatado um número elevado deles circulando pelos corredores entre as barracas na feira livre, devido aos restos de alimentos, resultando numa ameaça de disseminação de zoonoses.

As instalações sanitárias utilizadas pelos feirantes do mercado público e da feira livre estão localizadas dentro do mercado público, porém, estas instalações estavam em reforma/manutenção. Assim, no momento da pesquisa foi observada a presença de banheiros químicos. No lavatório não possuía sabão líquido e papel toalha para higiene pessoal dos feirantes e /ou consumidores.

Martins e Ferreira (2018) ao avaliarem as instalações sanitárias de uma feira livre do município de Macapá-AP detectaram banheiros sem nenhuma condição higiênica, os lavatórios não possuíam água corrente para higienização dos feirantes e /ou consumidores.

Segundo informações fornecidas pelo diretor do mercado público, a cada seis meses é feita a dedetização para o controle de vetores/pragas urbanas. No entanto, a dedetização somente é válida, quando existe a conscientização da importância de manter os locais 
Revista Ambientale

Revista da Universidade Estadual de Alagoas/UNEAL

e-ISSN 2318-454X, Ano 12, Vol. 12 (4), outubro/dezembro (2020)

higienizados. Assim, poderá existir o controle integrado, o qual requer que haja higienização nos ambientes, pois, a presença de lixo atrai insetos e roedores.

\section{Conclusão}

Após avaliação dos itens relacionados à comercialização de alimentos perecíveis (frutas, hortaliças, carnes e pescados), no mercado público e feira livre, pôde-se constatar que as normas referendadas na RDC $N^{\circ}$ 216/2004 da ANVISA não são cumpridas na maioria dos aspectos observados, principalmente, na feira livre.

A feira livre é ambiente desfavorável para a venda de alimentos perecíveis, não possui estrutura mínima para que possam ser aplicadas as normas higiênico-sanitárias. O mercado público apesar de ter uma melhor infraestrutura, percebe-se que os feirantes não obedecem a legislação no quesito, por exemplo, manter os produtos cárneos sob refrigeração.

Todos os autores estudados avaliaram como negativos a maioria dos itens analisados nas feiras livres, evidenciando o caráter precário da comercialização dos produtos de origem animal, principalmente, nas pequenas cidades do interior.

\section{Conflito de interesses}

Os autores deste manuscrito não declararam conflitos de interesse. 


\section{Referências}

ARAPIRACA, Prefeitura de Arapiraca, 2017. Disponível em:

//web.arapiraca.al.gov.br/2017/10/feira-livre-fez-historia-e-torna-arapiraca-referencia regional/. Acesso em 01 de dez de 2018.

BARBOSA, F. H. F.; MONTEIRO, J. F; SILVA-JÚNIOR, A. C. S.; Aspectos higiênico sanitários na comercialização no mercado de pescado igarapé das mulheres, Macapá. Biota Amazônia, v. 6, n.4, 2016.

BRASIL. Ministério da Saúde. Agência Nacional de Vigilância Sanitária. Resolução RDC no 216, de 15 de setembro de 2004. Dispõe sobre Regulamento Técnico de Boas Práticas para Serviços de Alimentação. Diário Oficial da União. Brasília, DF, 2004.

CARNEIRO, F. L. Avaliação das condições higiênico-sanitárias das carnes comercializadas na feira livre do município de Esperança - PB. Trabalho de Conclusão do Curso de Medicina Veterinária da Universidade Federal da Paraíba - UFPB, 2018.

CAVALCANTI, C. R.; PAULINO, F. de O.; MAYER, K. D. G.; SILVA, F. F. da; GOMES, V. D. S.; SANTOS, F. G. de A. Avaliação e diagnóstico das condições de comercialização de alimentos nas feiras livres no estado da Paraíba. Arq. Ciênc. Vet. Zool. UNIPAR, Umuarama, v. 17, n. 3, p. 167-172, jul./set. 2014.

CONSTANTINIDO, G. A saúde do pescado depende diretamente da saúde do ambiente. Higiene Alimentar, v.8, n.32, p.5-6, 1994. Trabalho apresentado no SEMINÁRIO DE VIGILÂNCIA SANITÁRIA PESQUEIRA: QUALIDADE DE PESCADOS, 1., 1994, São Paulo.

COUTINHO, E. P; OLIVEIRA, A. T; FRANCISCO, M. S; SILVA. M. J. da; SILVA, J. M. S. S. da; AZEREDO, L. P. M. Avaliação das Condições Higiênico-Sanitárias da Manipulação e Comercialização de Carnes Vermelhas e Aves nas Feiras Livres dos Municípios de Bananeiras e Solânea, PB. II JORNADA NACIONAL DA AGROINDÚSTRIA, 2007.

FARIAS, K. C, et. al. Avaliação das condições higiênico-sanitárias de alimentos comercializados no mercado municipal e na feira livre do município de Hidrolândia-CE. $\mathbf{V}$ CONNEPI, p.1-7, Ceará, 2010.

FARIAS, M. C. A. Avaliação das condições higiênico - sanitárias do pescado beneficiado em indústrias paraenses e aspectos relativos à exposição para consumo em Belém - Pará.

Dissertação (Mestrado) - Universidade Federal do Pará/UFPA, Belém, 2006. 
FERREIRA, F.R.B.; SILVA, N.G.; MOURA, E.A.; SILVA, C.G.M. Condições higiênicosanitárias das carnes comercializadas em feiras livres de municípios da zona da mata nortePE. 2010. In: X Jornada de Ensino, Pesquisa e Extensão da UFRPE, 10. Anais. 2010.

GOMES, P. M. A.; BARBOSA, J. G.; COSTA, E. R.; JÚNIOR, I. G. S. Avaliação das condições higiênicas sanitárias das carnes comercializadas na feira livre do município de Catolé do Rocha-PB. Revista Verde de Agroecologia, v. 7, n. 1, p. 225-232, 2012.

IBGE. Instituto Brasileiro de Geografia e Estatística (2019). Disponível em:

<https://www.ibge.gov.br/cidades-e-estados/al/arapiraca.html>. Acesso em 27 de out de 2019.

MARTINS, A. G.; FERREIRA, A. C. S. Caracterização das condições higiênico-sanitária das feiras livres da cidade de Macapá e Santana-AP. Rev. Arq. Científicos (IMMES). Macapá, v. 1, n. 1, p. 28-35, 2018.

MEDEIROS-JÚNIOR, E. F.; EIRAS, B. J. F.; RODRIGUES, E. C.; ALVES, M. M. Avaliação higiênico-sanitária do pescado comercializado na cidade de Bragança, Pará. Nutritime Revista Eletrônica, v. 12, n. 5, 2015.

OLIVEIRA, A. B. A; PAULA, C. M. D; CAPALONGA, R; CARDOSO, M. R. I; TONDO, E. C. Doenças transmitidas por alimentos, principais agentes etiológicos e aspectos gerais: uma revisão. Revista Hospital das Clínicas de Porto Alegre - HCPA. 2010; 30(3): 279-289.

OLIVEIRA, R. B. A.; ROLIM, M. B. Q.; MOURA, A. P. B. L.; MOTA, R. A.; Avaliação higiênico-sanitária dos boxes que comercializam carnes em dois mercados públicos da cidade do Recife-PE/Brasil, Revista de Medicina Veterinária, v. 2, n. 4, p. 10-16, 2008.

OLIVEIRA, J. D.; SILVA, T. R. S.; CORREIA, M. G. S. Fatores Determinantes da Qualidade Nutricional da Carne Bovina. Cadernos de Graduação-Ciências Biológicas e da Saúde, Aracaju, v.1, n.16, p.37- 46, mar. 2013.

SANTOS, D. B.; MACHADO, M. S.; SAMPAIO, A. H. R.; VIEIRA, L. M. Avaliação das condições higiênico-sanitárias da feira livre da colônia de pescadores do município de UruçuíPI. Enciclopédia Biosfera, v. 9, n. 16, p. 2433-2443, 2013.

SILVA, I. B.; MENELAU, A. S. Condições higiênicas sanitárias no comércio de banana em diferentes mercados públicos e feiras livres no Recife. Revista Científico, Fortaleza, CE, v. 14, n. 29, p. 125-140, 2015.

SILVA-JÚNIOR, A. C. S. A sanidade do pescado e sua comercialização na feira do Perpétuo Socorro, Macapá-AP: Educação em saúde como identificação e prevenção de parasitoses junto à comunidade. Trabalho de conclusão de curso (Graduação) - Universidade Federal do Amapá/UNIFAP, Macapá, 2008. 
Revista Ambientale

Revista da Universidade Estadual de Alagoas/UNEAL

e-ISSN 2318-454X, Ano 12, Vol. 12 (4), outubro/dezembro (2020)

SILVA-JÚNIOR, A. C. S. Comercialização de peixes na feira do pescado, Macapá-AP:

Aspectos higiênico-sanitários e avaliação microbiológica de peixe e do gelo utilizado na sua conservação. Dissertação (Mestrado) - Universidade Federal do Amapá/UNIFAP, Macapá, 2013.

SOUSA, S. M. N. Análise das condições higiênico-sanitárias das frutas e hortaliças comercializadas no mercado municipal e em uma feira-livre da cidade de Capanema, Pará. Trabalho de Conclusão de Curso de Bacharel em Ciências Biológicas pela Universidade Federal Rural da Amazônia, 2017.

XAVIER, A. Z. P; VIEIRA, G. D. G; VALVERDE, L. O. M; PEREIRA, V. S. Condições higiênicas sanitárias das feiras livres do município de Governador Valadares. Trabalho de Monografia. Universidade Vale do Rio Doce. 2009. 